\title{
Article
}

\section{Environmental regulation and green productivity: Evidence of the moderating effect of Chinese environmental decentralization}

\author{
Zhen Chen ${ }^{1, *}$ \\ 1 Business School, Beijing Normal University, Beijing 100875, China; 18810906546@163.com \\ * Correspondence: ZhenChen06@126.com;
}

\begin{abstract}
Environmental decentralization (ED), as an institutional factor, impacts the effectiveness of environmental regulation to achieve green productivity (GTFP). Based on panel data of 30 Chinese provinces from 2001 to 2015, this paper assessed GTFP, whose value is higher than 1. A two-step generalized method of moments (GMM) was employed to test the effects of environmental regulations (environmental protection investment (ENV) and pollutant discharge fees (PDF)) on GTFP with or without being influenced by ED. Without the impact of ED, GTFP is significantly inhibited by ENV, while it is significantly promoted by PDF. Under the influences of environmental decentralization from the central to the local authorities (TED), ENV has insignificantly negative effects on GTFP; contrarily, PDF have positive effects on GTFP. As for moderating effects of environmental decentralization at different administrative levels within a province, the degree of provincial environmental decentralization (PTED) should be decreased, while the degrees of prefectural ED (UTED) and county-level ED (CTED) should be increased. Generally, rationally allocating environmental management power among various administrative levels in a province increases the effectiveness of PDF to achieve green productivity while decreases the negative effects of ENV.
\end{abstract}

Keywords: Environmental regulation; Green productivity; Dynamic panel model; Environmental decentralization

\section{Introduction}

In recent decades, green growth has been considered a significant strategy for sustainable economic growth, and it has gradually replaced traditional economic growth since it considers environmental sustainability while obtaining goods and services. Green productivity is the dominant driver for sustainable economic growth [1] and reduces pollutant emissions or improves energy efficiency when the desired output is maintained or increased [2]. In the early 2000s, China has made achievements in economic growth; nevertheless, the rapid growth model, which relies more on lowcost labor (Labor) and fixed-asset investment growth (Capital) than total factor productivity (TFP) or green total factor productivity (GTFP) (Figure 1), has also caused severe environmental crises, such as air pollution [3]. Therefore, China is facing unparalleled problems to achieve green productivity [4] due to environmental deterioration and a decrease in environmental bearing capacity. 


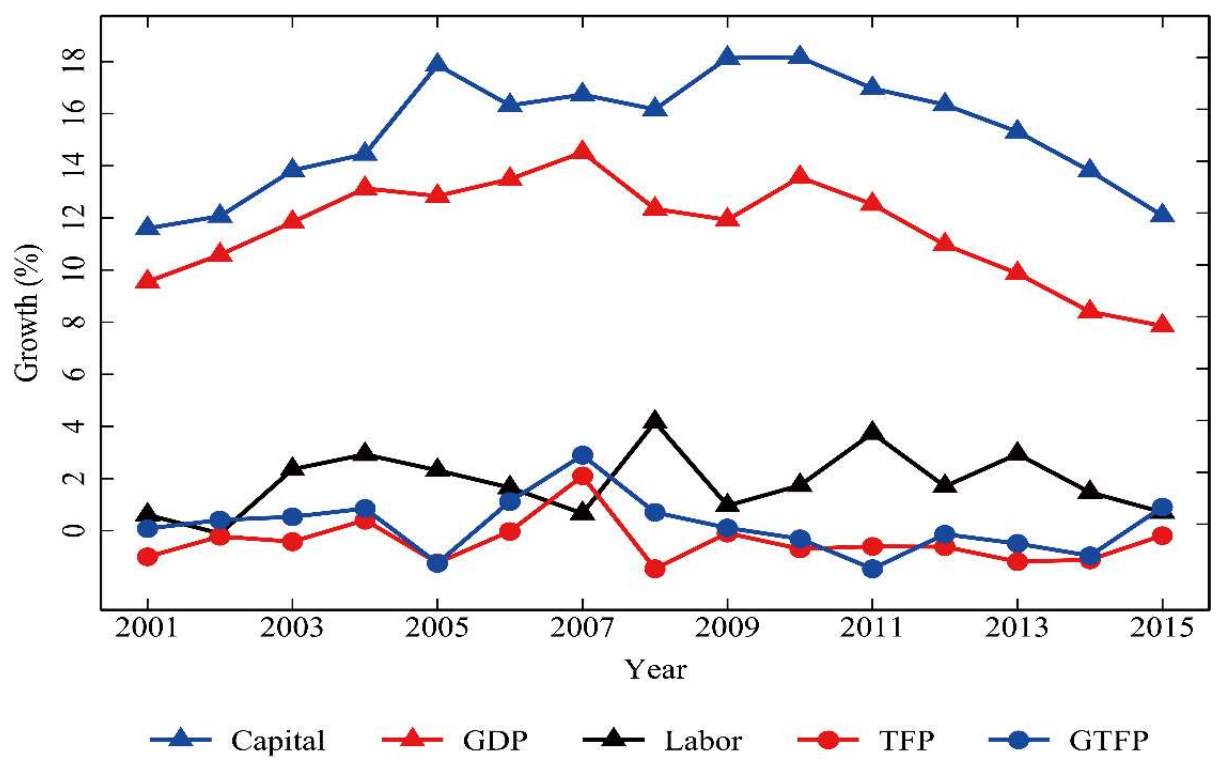

Figure 1. Growth in fixed-asset investment, GDP, labor force, GTFP, and TFP from 2001 to 2015 in China.

Environmental protection policy implemented by local governments is of great significance to improvement in GTFP [5]. In recent decades, the central government of China has formulated a series of environmental protection policies [6]. According to the 11th Five-Year Plan in 2006, a 10\% reduction in the emissions of chemical oxygen demand (COD) and sulfur dioxide (SO2) was proposed to become a binding indicator in each province, and target responsibility and performance evaluation systems of environmental protection among local authorities are suggested to establish. Furthermore, an $8 \%$ reduction in emissions of ammonia nitrogen, and nitrogen oxide was required in the 12th Five-Year Plan in 2011. In 2015, "Environmental Protection Law" stipulated that "the local governments are in charge of environmental quality in their territories." It is evident that China's environmental policies have focused on reducing pollutant emissions and have emphasized the environmental responsibility of local governments while imposing constraints on enterprise production, which slowed local economic growth. For better political performance, local governments will implement these environmental protection policies using different environmental regulations like ENV, PDF, and environmental taxes. As a result, it is necessary to determine how various environmental regulations affect GTFP. Further, since economic development levels and environmental conditions vary in different parts of China [7], the correlation of environmental regulation to GTFP also differs in those areas.

A wealth of studies have investigated the effects of environmental regulation on GTFP [8,9]. Some investigated the impacts of environmental regulation from the perspective of fiscal decentralization $[10,11]$. However, few have investigated the effects of environmental regulation on GTFP, taking the influence of environmental decentralization into account at the same time. Reasonable environmental decentralization, appropriately allocating environmental protection power and responsibility among various administrative authorities, ensures the effectiveness of environmental regulation. Decentralization reform has a long history in China ${ }^{1}$. This process shows that China's central

\footnotetext{
${ }^{1}$ In the first stage (1973-1993), the establishment of the National Environmental Protection Leading Group in 1973 marked the beginning of decentralized environmental management. The State Bureau of Environmental Protection, which used to be part of the Ministry of Urban and Rural Environmental Protection as the direct
} 
government has focused on reforming the environmental management system in recent years and has gradually increased the degree of ED, encouraging local governments to participate in environmental protection.

Notably, the tasks of local governments include environmental governance and economic growth. Whether local governments can carry out environmental regulation following public-interest demand is in close relation to the degree of ED, namely the autonomy of local governments in environmental pollution treatment and the allocation of environmental protection personnel. Moreover, local governments may execute environmental policies formulated by the central government inadequately, when the local governments' economic development goals conflict with the central environmental protection targets. Therefore, clarifying how ED affects environmental regulations is of significant value to achieving green development.

Further, China's environmental protection personnel are located at different administrative levels in a province. How does ED at different administrative levels affect the effects of environmental regulations on GTFP? More in-depth studies are required on this topic. The effects of environmental regulation on GTFP under the influence of ED are investigated in this paper, and the results provide an appraisal of the impact of environmental regulations, as well as pertinent recommendations for the vertical reform of environmental management, thus contributing to the green economy transformation of China.

\section{Literature review}

Much empirical literature has estimated the impact of environmental regulations on GTFP, but mixed results were reported. Telle and Larsson in 2007 [12] pointed out that environmental regulation positively affected environmental Malmquist productivity. Similarly, Zhang et al. in 2011 [2] observed significantly positive effects of environmental regulation on ETFP calculated by the Malmquist-Luenberger (ML) index. Manello in 2017 [13] estimated TFP growth considering environmental pollution and demonstrated that environmental regulation positively impacted the TFP growth in the chemical industry of Italy and Germany. However, the positive impact of environmental regulations is not always consistent because different environmental regulations are in distinct correlations to GTFP or ETFP [6]. Moreover, different environmental regulations have various effects on the green development of different areas in China [14]. Other factors influencing the effectiveness of environmental regulations include regulatory stringency [15], measurement of environmental regulation [16], time-lag [17], and fiscal decentralization [10].

Some researchers have argued that decentralization can decrease the efficiency of environmental policies [18] and increase environmental pollution [19]. Local authorities autonomously manage environmental affairs and often choose to relax environmental regulation for capital inflow, resulting in environmental degradation [20]. Others hold that local governments implement stringent environmental regulations as the degree of ED increases [21], which helps to reduce regional environmental pollution [22]. At present, in most studies of the environmental effects of ED [19], only a few considered the joint effects on the environment and economic growth [23]. However, fiscal decentralization can influence environmental quality indirectly and requires mediators, i.e., environmental regulations [10,11]. Similarly, ED indirectly impacts GTFP through environmental regulations, i.e., ENV and PDF. Furthermore, different countries have different ED systems. The U.S.

subordinate mechanism of the State Council, began to supervise and manage national environmental protection affairs in 1988. The second stage (1994-2007) witnessed China's deepening decentralization reform and the incorporation of environmental quality into the performance assessment of local governments. In the third stage (2008-2015), the Ministry of Environmental Protection was founded in 2008. Several environmental protection policies, such as energy conservation and emissions reduction administered by local governments, encouraged local authorities to protect the environment. In the fourth stage (2016-2019), vertical management of environmental protection in the provinces started in 2016. 
federal government gives environmental enforcement power to the state governments while following the laws, such as the Clean Water Act (CWA) [24]. In China, the management power of environmental affairs is delegated to local governments by the central government.

In short, although the effects of environmental regulation or ED on GTFP are estimated, some limitations remain. First, few researchers have estimated the joint effects of ED and environmental regulation on GTFP. Second, fiscal decentralization indicators have been widely used as proxy variables of ED. Third, most literature has focused on ED from the central to local governments, but little research has estimated the ED below the provincial level.

Therefore, this study provides three main contributions. First, from the perspectives of investment and charge, the ENV and PDF are used as proxy variables of different environmental regulation tools on to investigate their effects on GTFP. Second, using dynamic changes in environmental management staff at different administrative levels, an index of ED is created to reflect changes in environmental management system. Third, ED, as a moderating variable, is important in the effectiveness of environmental regulation to achieving; however, it does not directly impact GTFP. Thus, this paper provides the following new insights. TED has no regulatory effect on ENV but has positive effects on PDF, indicating that TED and PDF jointly promote GTFP. In general, the moderating effects of the sub-indicators of TED, namely environmental administrative decentralization (AED), environmental supervision decentralization (SED), and environmental monitoring decentralization (MED), on ENV and PDF are consistent with that of TED. Additionally, regarding environmental decentralization at different administrative levels in a province, the results show that PTED do not have positive moderating effects. UTED has positive moderating effects on ENV, whereas CTED have significantly positive moderating effects on PDF.

\section{Materials and Methods}

\subsection{Estimation methods}

In general, the factors affecting economic growth and pollutant emissions have similar impacts on GTFP. Some researchers focused on whether environmental regulations promoted or curbed GTFP and investigated the impacts of various intensities of environmental regulation [25] and different implementation mechanisms [5,6]. The one-phase lag of the dependent variable has been used as an explanatory variable [26]. The GMM model was used to investigate the dynamics of panel data and control endogeneity and unobserved time-variable factors [27]. The effects of environmental regulation on GTFP were estimated as follows:

$$
\operatorname{GTFP}_{i, t}=a_{0}+b_{1} \operatorname{GTFP}_{i, t-1}+a_{1} E R_{i, t}+\sum_{k=1}^{5} s_{k} \text { Controls }_{i, t}+u_{i}+g_{t}+e_{i, t}
$$

Where $E R_{i, t}$ includes the intensity of investment in ENV and the intensity of PDF, where the subscripts represent the province $i$ and year $t$. The individual and time effects are denoted by $u_{i}$ and $\gamma_{\mathrm{t}}$, respectively. $\varepsilon_{\mathrm{it}}$ is the disturbance term. GTFP $P_{i, t-1}$ represents the one-year lag in the variable of GTFP. Control variables (Controls) include five variables: economic development level (RGDP), foreign direct investment (FDI), post and telecommunications (TELE), industrial structure (STRUCT), technology innovation (TECH), and population density (POPU).

A cross-term of environmental regulation and environmental decentralization was added to equation (1) to investigate the moderating effect of environmental decentralization on environmental regulation (Equation (2))

$$
\operatorname{GTFP}_{i, t}=a_{0}+b_{1} \operatorname{GTFP}_{i, t-1}+a_{1} e r_{i, t}+a_{2} E R_{i, t} \times E D_{i, t}+a_{3} E D_{i, t}+\sum_{k=1}^{5} s_{k} \text { Controls }_{i, t}+u_{i}+g_{t}+e_{i, t}
$$

Where the coefficient $a_{2}$ represents the effect of the cross-term $E R_{i, t} \times E D_{i, t} \cdot E D_{i, t}$ includes environmental decentralization and its sub-indices, while the other variables remain unchanged.

The effects of the threshold of TED, PTED, UTED, and CTED on GTFP are assessed by dynamic threshold panel model, as the following model is constructed: 


$$
\begin{aligned}
& \operatorname{GTFP}_{i, t}=a_{0}+b_{1} \operatorname{GTFP}_{i, t-1}+a_{1} E R_{i, t}+a_{2} E R_{i, t} \times E D_{i, t} \cdot I\left(q_{i, t} \leq \theta\right)+a_{4} E R_{i, t} \times E D_{i, t} \cdot I\left(q_{i, t}>\theta\right) \\
& +\sum_{k=1}^{5} d_{k} \text { control }_{i, t}+u_{i}+g_{t}+e_{i, t}
\end{aligned}
$$

Where I(.) the function uses the value of 0 or $1 ; q_{i . t} \leq \theta$ represents the threshold variable, namely, the total environmental decentralization at different administrative levels. $\theta$ represents the threshold value; $\alpha_{2}$ and $\alpha_{4}$ denote the impact of $E R_{i, t} \times E D_{i, t}$ on $G T F P_{i, t}$ for $q_{i . t} \leq \theta$ and $q_{i . t}>\theta$, respectively. A random grid search is used to obtain the minimum value of the Sargan statistics and optimal threshold $\theta$ [28].

\subsection{Variables}

\subsubsection{Green productivity}

For the explained variable, the GTFP is used to represent GTFP, which is calculated using the Max DEA software. Referring to the methods of Färe et al. (2007) [29], Oh (2010) [30], and Li and Wu (2018) [31], the GTFP is calculated in 30 provinces in the year of 2000-2015 using the Global ML (GML) index as follows:

$$
G M L_{i, t}^{i, t+1}=\frac{1+\overrightarrow{S_{V}^{G}}\left(x^{i, t}, y^{i, t}, z^{i, t} ; g^{x}, g^{y}, g^{z}\right)}{1+\overrightarrow{S_{V}^{G}}\left(x^{i, t+1}, y^{i, t+1}, z^{i, t+1} ; g^{x}, g^{y}, g^{z}\right)}
$$

Where $x$ represents the input variables that include the labor force, capital stock, and energy consumption; $y$ is the desired output that is the GDP measured in 2000 prices; $z$ represents the undesirable output, which is the amount of industrial $\mathrm{SO}_{2}, \mathrm{COD}$, and solid waste. $g^{x}, g^{y}, g^{z}$ represent the direction vector of decreasing $x$, increasing $y$, and decreasing $z$, respectively. $\overrightarrow{S_{V}^{G}}\left(x^{i, t}, y^{i, t}, z^{i, t} ; g^{x}, g^{y}, g^{z}\right)$ refers to the global distance function.

If $G M L_{i, t}^{i, t+1}$ is greater than 1, the GTFP increases from $t$ to $t+1$, and vice versa. Since 2000 is used as the base period (the GTFP in 2000 is 1), the GTFP in 2001 is the GTFP in 2000 multiplied by the GML index in 2001, and so on. Additionally, TFP was determined using the Malmquist index without considering the environmental factors and energy consumption.

\subsubsection{Environmental regulation}

The core explanatory variables are environmental regulations (ENV or PDF). Environmental laws and regulations promulgated by the local governments are identical to those of the central governments. The diversity of environmental protection in different areas is reflected in the ENV and PDF. Based on data availability, Equation (5) is used to measure the level of ENV [32].

$$
E N V_{i t}=\frac{E N V I_{i t} / P_{i t}}{P_{i t} / G D P_{i t}}
$$

Where $E N V I_{i t}$ is the investment in industrial pollution treatment, and $P_{i t}$ indicates the industrial output in each province. $P_{i t} / G D P_{i t}$ is used to correct $E N V I_{i t} / P_{i t}$ to avoid errors resulting from the differences of the industrial structure [33]. China imposed PDF in 1982; PDF are primarily regulated by the market in China. These fees are sources of funds for pollution treatment and have exhibited continuously rapid growth in 2001-2015, increasing from 6.218 billion in 2001 to 17.846 billion in 2015. This paper replaced $E N V I_{i t}$ in Equation (5) with the PDF in the different provinces.

\subsubsection{Environmental decentralization}

The purpose of environmental decentralization is to ensure environmental protection while supplying public goods and services. Sigman (2007) [34] pointed out that it is very difficult to develop an environmental decentralization index. The calculation methods of environmental decentralization include the proportion of the state's environmental regulations of federal regulations [35], the 
changes in personnel in the central or local environmental protection system [19], and the use of dummy variables [36].

The difficulties in calculating the decentralization degree occur because the relationships between the different levels are intricate. With reference to, the calculation formula of total environmental decentralization is expressed as follows:

$$
T E D_{i t}=\left[\frac{L E P_{i t} / L P O P_{i t}}{E P_{t} / P O P_{t}}\right] \times\left[1-G D P_{i t} / G D P_{t}\right]
$$

Where $T E D_{i t}$ represents environmental decentralization from the central to the local authorities, i.e., the province, municipality, and county. $L E P_{i t}$ represents all employees in every province's environmental protection systems; similarly, $E P_{i t}$ represents all staff in the whole country's environmental protection systems. $L P O P_{i t}$ represents each province's population and $P O P_{i t}$ represents the national population; $\left[1-G D P_{i t} / G D P_{t}\right]$ is an economic reduction factor minimizing the endogenous problem.

The effects of different types of environmental decentralization are influenced by the diversity of environmental management affairs. Additionally, there are three sub-indices of environmental decentralization are used, namely, environmental administrative decentralization (AED), environmental supervision decentralization (SED), and environmental monitoring decentralization (MED). Equation (6) is used to calculate the three sub-indices by replacing $L E P_{i t}$ and $E P_{t}$ with the all administrative (supervising or monitoring) personnel in local environmental authority and employees in national environmental systems.

China's environmental protection system consists of a block system under the dual management of the Ministry of Environmental Protection and the local authorities. Therefore, personnel distribute in the environmental protection systems at four administrative levels, which include the central, provincial, prefectural, and county levels in China. Given the available data, selected three administrative levels (provincial, prefectural, and county-level) are selected to calculate the TED and the sub-indices. For instance, the calculation formula of the provincial total environmental decentralization (PTED) is equation (6). $L E P_{i t}$ and $E P_{t}$ are replaced with all employees of the provincial environmental protection systems in each province and all provincial employees of the environmental protection systems in China. Provincial AED (PAED), provincial SED (PSED), and provincial MED (PMED) are determined using the same method. The calculation formulas of the TED and the sub-indices at the prefectural or county-level consider the provincial level of total environmental decentralization and the sub-indices. Those include the prefectural TED (UTED), prefectural AED (UAED), prefectural SED (USED), prefectural MED (UMED), county-level TED (CTED), county-level AED (CAED), county-level SED (CSED), and county-level MED (CMED).

\subsubsection{Controls variables}

The ratio of the total posts and telecommunications to the provincial GDP is used to quantify the level of posts and telecommunications (TELE). Industrial structure (STRUCT) is measured by the proportion of the value-added of the secondary industrial products to the GDP. Technological innovation $(T E C H)$ is quantified by using the logarithmic value of the number of patent grants. Economic development level $(R G D P)$ is the logarithmic value of the per capita GDP [5]; Population density $(P O P U)$ is the logarithmic value of the population per square kilometer in the administrative area (per 10,000 people $/ \mathrm{km}^{2}$ ). Foreign direct investment $(F D I)$ is the ratio of foreign direct investment to regional GDP.

\subsection{Data description}

The sample interval is from 2001 to 2015 due to the unavailability of counting employees in prefectural or county-level environmental protection systems after 2015, and panel data are from China's 30 provinces. The data were obtained from the China Statistical Yearbook and the China 
Environmental Statistical Yearbook. Generally, the changes in the variables in Table 1 are relatively small, which minimizes the errors.

Table 1. The statistical description of the variables.

\begin{tabular}{|c|c|c|c|c|c|c|}
\hline Variables & $\mathrm{N}$ & Mean & Std. dev & Min & Median & Max \\
\hline GTFP & 450 & 1.014 & 0.161 & 0.662 & 1.004 & 1.893 \\
\hline ENV & 450 & 0.343 & 0.261 & 0.014 & 0.280 & 1.921 \\
\hline PDF & 450 & 0.357 & 0.253 & 0.057 & 0.293 & 1.379 \\
\hline TELE & 450 & 0.053 & 0.022 & 0.014 & 0.051 & 0.119 \\
\hline STRUCT & 450 & 0.394 & 0.080 & 0.131 & 0.411 & 0.530 \\
\hline TECH & 450 & 8.623 & 1.633 & 4.248 & 8.575 & 12.510 \\
\hline POPU & 450 & 0.218 & 0.139 & 0.006 & 0.195 & 0.631 \\
\hline RGDP & 450 & 0.770 & 0.774 & -1.210 & 0.827 & 2.369 \\
\hline FDI & 450 & 0.424 & 0.527 & 0.047 & 0.219 & 5.705 \\
\hline TED & 450 & 0.963 & 0.352 & 0.410 & 0.890 & 2.264 \\
\hline AED & 450 & 0.987 & 0.368 & 0.377 & 0.905 & 2.336 \\
\hline SED & 450 & 0.933 & 0.519 & 0.125 & 0.794 & 2.477 \\
\hline MED & 450 & 0.993 & 0.361 & 0.400 & 0.941 & 2.520 \\
\hline PTED & 450 & 0.098 & 0.092 & 0.020 & 0.067 & 0.571 \\
\hline PAED & 450 & 0.077 & 0.072 & 0.017 & 0.050 & 0.423 \\
\hline PSED & 450 & 0.029 & 0.032 & 0.000 & 0.015 & 0.184 \\
\hline PMED & 450 & 0.093 & 0.095 & 0.000 & 0.054 & 0.533 \\
\hline UTED & 450 & 0.238 & 0.134 & 0.000 & 0.209 & 0.876 \\
\hline UAED & 450 & 0.208 & 0.141 & 0.000 & 0.179 & 1.012 \\
\hline USED & 450 & 0.168 & 0.102 & 0.000 & 0.146 & 0.687 \\
\hline UMED & 450 & 0.324 & 0.192 & 0.000 & 0.277 & 1.329 \\
\hline CTED & 450 & 0.572 & 0.301 & 0.000 & 0.509 & 1.728 \\
\hline CAED & 450 & 0.702 & 0.336 & 0.000 & 0.618 & 1.992 \\
\hline CSED & 450 & 0.736 & 0.493 & 0.000 & 0.602 & 2.251 \\
\hline CMED & 450 & 0.577 & 0.328 & 0.000 & 0.531 & 2.044 \\
\hline
\end{tabular}

\section{Results}




\subsection{Analysis of green productivity}

Figure 2 shows the changes in the GTFP and TFP. The average GTFP was higher than the average TFP in all provinces, indicating that production moves towards fewer pollutant emissions under the condition [37]. Specifically, TFP ranged from 0.98 to slightly above $1(2004,2007)$, and GTFP ranged from slightly under 1 (2001, 2005, 2014, 2015) to 1.04. Between 2001 and 2015, GTFP and TFP have experienced some fluctuations. A similar trend was observed before 2007; the widest gap occurred in 2008 and then gradually narrowed.

The changes in the TFP in different areas were relatively small, whereas the changes in the GTFP were significant. The GTFP of eastern provinces was much higher than that of the central and western, where eastern, central, and western units are divided by the method of $\mathrm{Hu}$ and Wang ( 2020)[33]; it steadily increased from 2001 to 2010 and then slightly decreased in 2011-2014. In the eastern areas, the average GTFP was substantially higher than the TFP, indicating that production was moving towards less energy consumption and less pollution. In the central areas, the TFP was lower than the GTFP before 2009; however, it exceeded the GTFP significantly since then. The GTFP was lower than the TFP after 2003 in the west.
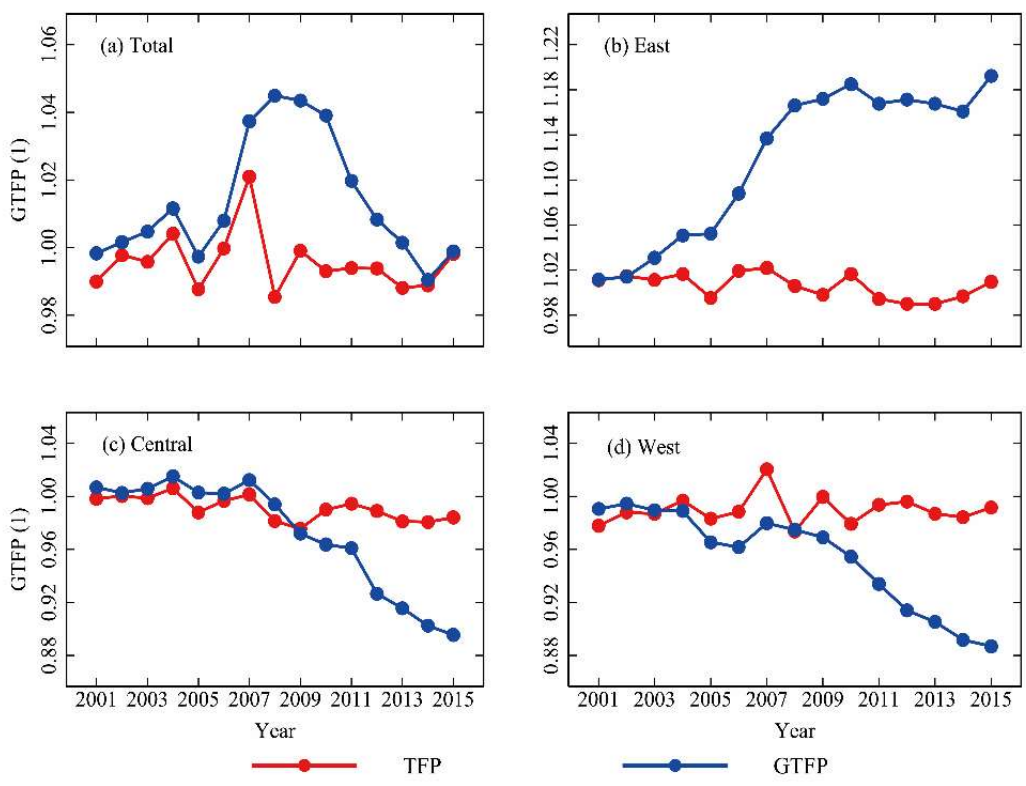

Figure 2. Changes in the GTFP and TFP of all provinces ((a) Total), eastern provinces ((b) East), central provinces ((c) Central), and western provinces ((d) West) in China from 2001 to 2015.

\subsection{Impacts of environmental regulation on green productivity}

In equation (2), the two-step difference GMM (DIFF_GMM) method addresses the endogenous problems resulting from a possible correlation between the dependent variable and the compound disturbance. The Sargan and Arellano-Bond tests were utilized to examine the validity of the instruments and to determine the existence of a second-order serial autocorrelation in error. Table 2 shows the effects of different environmental regulations on GTFP. The P-values of AR (2) are all larger than 0.1 ; therefore, the original hypothesis that there is a second-order serial autocorrelation is rejected. The Sargan test' results show that the selection of instruments is effective.

At the regional level, two dummy variables, eastern and central \& western, are included in the model. If the objects are in the eastern regions, then Dume $=1$, otherwise Dume $=0$. ER_eastern represents the cross-term ER $\times$ Dume; if the objects are in the central and west, then Dumw $=1$; otherwise, Dumw $=0$. ER_central \& western represents the cross-term $E R \times D u m w$.

Table 2. Impacts of different environmental regulations on GTFP 


\begin{tabular}{|c|c|c|c|c|}
\hline \multirow{2}{*}{ Variables } & \multicolumn{2}{|c|}{ National } & \multicolumn{2}{|c|}{ Regional } \\
\hline & ENV & PDF & ENV & PDF \\
\hline \multirow[t]{2}{*}{$\operatorname{GTFP}_{i, t-1}$} & $0.548^{* * *}$ & $0.647^{* * *}$ & $0.603^{* * *}$ & $0.630^{* * *}$ \\
\hline & $(0.020)$ & $(0.021)$ & $(0.025)$ & $(0.032)$ \\
\hline \multirow[t]{2}{*}{ ER } & $-0.013^{* * *}$ & $0.053^{* * * *}$ & & \\
\hline & $(0.002)$ & $(0.004)$ & & \\
\hline \multirow[t]{2}{*}{ ER_eastern } & & & $0.009^{*}$ & $-0.060^{*}$ \\
\hline & & & $(0.006)$ & $(0.048)$ \\
\hline \multirow[t]{2}{*}{ ER_central\&western } & & & $-0.032^{* * *}$ & $0.055^{* * *}$ \\
\hline & & & $(0.004)$ & $(0.004)$ \\
\hline \multirow[t]{2}{*}{ STRUCT } & $0.047^{* *}$ & $0.046^{* * *}$ & $0.044^{*}$ & $0.052^{* *}$ \\
\hline & $(0.047)$ & $(0.037)$ & $(0.048)$ & $(0.048)$ \\
\hline \multirow[t]{2}{*}{$\mathrm{TECH}$} & $0.202^{* * *}$ & $0.269^{* * *}$ & $0.209^{* * *}$ & $0.277^{* * *}$ \\
\hline & $(0.004)$ & $(0.003)$ & $(0.004)$ & $(0.005)$ \\
\hline \multirow[t]{2}{*}{ POPU } & $0.020^{* *}$ & $0.023^{* * *}$ & 0.014 & $0.018^{* *}$ \\
\hline & $(0.002)$ & $(0.002)$ & $(0.002)$ & $(0.002)$ \\
\hline \multirow[t]{2}{*}{ TELE } & $0.062^{* * *}$ & $0.053^{* * *}$ & $0.048^{* * *}$ & $0.054^{* * *}$ \\
\hline & $(0.041)$ & $(0.064)$ & $(0.076)$ & $(0.071)$ \\
\hline \multirow[t]{2}{*}{ RGDP } & $-0.145^{* * *}$ & $-0.182^{* * *}$ & $-0.167^{* * * *}$ & $-0.202^{* * *}$ \\
\hline & $(0.007)$ & $(0.005)$ & $(0.010)$ & $(0.006)$ \\
\hline \multirow[t]{2}{*}{ FDI } & $-0.003^{* *}$ & 0.002 & $-0.007^{* * *}$ & -0.003 \\
\hline & $(0.000)$ & $(0.001)$ & $(0.001)$ & $(0.001)$ \\
\hline AR (1) & $-1.381^{*}$ & $-1.560^{*}$ & $-1.518^{*}$ & $-1.570^{*}$ \\
\hline AR (2) & 0.822 & 0.668 & 0.683 & 0.750 \\
\hline \multirow[t]{2}{*}{ Sargan } & 26.056 & 27.464 & 23.704 & 26.380 \\
\hline & [1.000] & [1.000] & [0.999] & [1.000] \\
\hline \multirow[t]{2}{*}{ Wald test } & 9849.55 & 3473.39 & 2993.61 & 4074.98 \\
\hline & [0.000] & {$[0.000]$} & {$[0.000]$} & {$[0.000]$} \\
\hline
\end{tabular}

Note: standard errors in parentheses; ${ }^{*} \mathrm{p}<0.10,{ }^{* *} \mathrm{p}<0.05,{ }^{* *} \mathrm{p}<0.001$; the numbers in [] are the P-values of the corresponding test statistics.

As for the national level, the coefficient of ENV is significantly negative. Lanoie et al. (2008)[32] investigated the TFP growth of manufacturing sectors in Quebec (Canada) and found that the oneyear lagged impacts of investment in pollution-control equipment on TFP were significantly negative; by contrast, the three-year lagged effects were significantly positive. Therefore, the positive effects of environmental protection investment on green productivity have a relatively long lag period. From the perspective of regional diversity, the coefficient of ENV is significantly positive in the eastern areas, while it is significantly negative in the central and western areas.

The coefficient of PDF is non-significantly positive at the national level, significantly negative in the eastern regions, and significantly positive in the central and western areas. The "compliance cost" in the eastern provinces is higher than that of the central and west if the marginal cost of pollutant treatment is the same in the three areas [38]. As a result, the PDF does not affect GTFP in the east. Moreover, PDF are the sources of funds for pollution treatment and indirectly promote GTFP in the central and west. 
Additionally, RGDP is significantly negative, which is in accordance with the point of view that rapid economic growth causes low energy efficiency or aggravate pollutant emissions [39]. FDI has an insignificant effect on GTFP. It boosts GDP growth and technical progress and inhibits GTFP by contributing to environmental pollution. If the boosting effect exceeds the inhibiting effect, then FDI helps enhance GTFP and vice versa. STRUCT has significantly positive impacts on GTFP, indicating that GTFP substantially increases with the upgrade of China's industrial structure. TECH has significantly positive effects on GTFP, which is in agreement with the results of Guo et al. in 2017 [8]. POPU significantly promotes GTFP growth, which is attributed to the fact that an increase in POPU has economies of scale effects on energy consumption and decreases pollutant discharge. TELE has significantly positive effects on GTFP.

\subsection{The moderating effect of environmental decentralization}

4.3.1 The moderating effect of environmental decentralization between the central and local authorities

Environmental decentralization has been implemented in China for years and requires deeper investigation; thus, the cross-term effects of ER $\times E D(E N V \times T E D$, ENV $\times A E D$, ENV $\times S E D$, or ENV $\times$ MED; PDF $\times$ TED, $P D F \times A E D, P D F \times S E D$, or PDF $\times$ MED) were included in equation (2). For example, the effect of a change in ENV can be estimated using the partial derivatives of equation (1) and equation (2); namely, $\alpha_{1}+\alpha_{2}$ TED, $\alpha_{1}+\alpha_{2}$ AED, $\alpha_{1}+\alpha_{2}$ SED, $\alpha_{1}+\alpha_{2}$ MED, where $\alpha_{1}$ represents the coefficient of ENV, $\alpha_{2}$ is the coefficient of ENV $\times$ TED, ENV $\times \mathrm{AED}, \mathrm{ENV} \times \mathrm{SED}$, or ENV $\times \mathrm{MED}$. The effects of a change in PDF are measured using the same methods.

From the moderating effects of environmental decentralization on the effectiveness of ENV to achieving GTFP, it is found that $\alpha_{1}<0$ and $\alpha_{2}<0$, the coefficients of ENV $\times$ TED and ENV $\times$ AED are non-significant, and the coefficients of ENV $\times$ SED and ENV $\times$ MED are significant. These results indicate that under the influence of SED and MED, the ENV has significantly inhibited GTFP.

As for the moderating effects of environmental decentralization on PDF, it is found that $\alpha_{1}>0$ and is statistically significant. The coefficients of PDF $\times$ TED, PDF $\times A E D, P D F \times S E D$, and PDF $\times$ MED are significantly positive, indicating that the GTFP promotive effects of the PDF are affected by TED and its sub-indices. When ED is at a very high level, $\alpha_{1}+\alpha_{2}>0$, implying that GTFP increases with an increase in the PDF.

Table 3. Estimated results of the moderating effects of different types of environmental decentralization.

\begin{tabular}{|c|c|c|c|c|c|c|c|c|}
\hline \multirow{2}{*}{ Variables } & \multicolumn{4}{|c|}{ ENV } & \multicolumn{4}{|c|}{ PDF } \\
\hline & TED & AED & SED & MED & TED & AED & SED & MED \\
\hline \multirow[t]{2}{*}{$\mathrm{GTFP}_{\mathrm{i}, \mathrm{t}-1}$} & $0.576^{* * *}$ & $0.567^{* * *}$ & $0.612^{* * *}$ & $0.585^{* * *}$ & $0.626^{* * *}$ & $0.628^{* * *}$ & $0.614^{* * *}$ & $0.603^{* * *}$ \\
\hline & $(0.022)$ & $(0.025)$ & $(0.024)$ & $(0.029)$ & $(0.034)$ & $(0.031)$ & $(0.028)$ & $(0.036)$ \\
\hline \multirow[t]{2}{*}{ ER } & $-0.017^{* * *}$ & $-0.022^{* * *}$ & $-0.018^{* * *}$ & $-0.019^{* * *}$ & $0.073^{* * *}$ & $0.068^{* * *}$ & $0.079^{* * *}$ & $0.063^{* * *}$ \\
\hline & $(0.004)$ & $(0.003)$ & $(0.003)$ & $(0.002)$ & $(0.006)$ & $(0.003)$ & $(0.005)$ & $(0.004)$ \\
\hline \multirow[t]{2}{*}{$\mathrm{ER} \times \mathrm{ED}$} & -0.008 & $-0.013^{* * * *}$ & $-0.015^{* * *}$ & 0.003 & $0.065^{* * *}$ & $0.028^{* * *}$ & $0.078^{* * *}$ & $0.063^{* * *}$ \\
\hline & $(0.056)$ & $(0.009)$ & $(0.008)$ & $(0.006)$ & $(0.019)$ & $(0.005)$ & $(0.009)$ & $(0.012)$ \\
\hline \multirow[t]{2}{*}{ ED } & 0.147 & $0.082^{* * *}$ & $0.063^{* *}$ & 0.025 & $-0.039^{*}$ & $0.052^{* * *}$ & $-0.052^{*}$ & $-0.112^{* * * *}$ \\
\hline & $(0.051)$ & $(0.007)$ & $(0.010)$ & $(0.008)$ & $(0.011)$ & $(0.006)$ & $(0.009)$ & $(0.009)$ \\
\hline \multirow[t]{2}{*}{ STRUCT } & $0.050^{* * *}$ & $0.067^{* * *}$ & 0.046 & $0.041^{*}$ & $0.045^{* *}$ & $0.050^{* *}$ & $0.054^{* * *}$ & $0.049^{* * *}$ \\
\hline & $(0.045)$ & $(0.052)$ & $(0.062)$ & $(0.046)$ & $(0.044)$ & $(0.045)$ & $(0.041)$ & $(0.038)$ \\
\hline \multirow[t]{2}{*}{$\mathrm{TECH}$} & $0.215^{* * *}$ & $0.241^{* * *}$ & $0.224^{* * *}$ & $0.226^{* * *}$ & $0.299^{* * *}$ & $0.300^{* * *}$ & $0.308^{* * *}$ & $0.290^{* * *}$ \\
\hline & $(0.004)$ & $(0.004)$ & (0.005) & $(0.004)$ & $(0.003)$ & $(0.004)$ & $(0.004)$ & $(0.003)$ \\
\hline
\end{tabular}




\begin{tabular}{lcccccccc} 
POPU & $0.019^{* *}$ & $0.028^{* * * *}$ & $0.029^{* * *}$ & $0.014^{*}$ & $0.014^{*}$ & $0.014^{* * *}$ & 0.013 & $0.023^{* * * *}$ \\
& $(0.002)$ & $(0.002)$ & $(0.002)$ & $(0.002)$ & $(0.002)$ & $(0.001)$ & $(0.002)$ & $(0.002)$ \\
TELE & $0.055^{* * *}$ & $0.048^{* * *}$ & $0.050^{* * *}$ & $0.056^{* * *}$ & $0.055^{* * *}$ & $0.052^{* * * *}$ & $0.054^{* * *}$ & $0.056^{* * *}$ \\
& $(0.048)$ & $(0.055)$ & $(0.058)$ & $(0.056)$ & $(0.061)$ & $(0.073)$ & $(0.064)$ & $(0.059)$ \\
\multirow{2}{*}{ RGDP } & $-0.164^{* * *}$ & $-0.180^{* * *}$ & $-0.172^{* * *}$ & $-0.167^{* * *}$ & $-0.198^{* * *}$ & $-0.194^{* * *}$ & $-0.197^{* * *}$ & $-0.210^{* * *}$ \\
& $(0.008)$ & $(0.008)$ & $(0.008)$ & $(0.008)$ & $(0.006)$ & $(0.007)$ & $(0.008)$ & $(0.006)$ \\
FDI & $-0.012^{* * *}$ & 0.020 & 0.042 & $-0.013^{* * * *}$ & $-0.003^{* * *}$ & $0.003^{*}$ & -0.000 & $0.002^{*}$ \\
& $(0.001)$ & $(0.006)$ & $(0.012)$ & $(0.001)$ & $(0.000)$ & $(0.001)$ & $(0.001)$ & $(0.000)$ \\
AR (1) & $-1.438^{*}$ & $-1.431^{*}$ & $-1.491^{*}$ & $-1.447^{*}$ & $-1.483^{* *}$ & $-1.514^{* *}$ & $-1.471^{*}$ & $-1.444^{*}$ \\
AR (2) & 0.732 & 0.731 & 0.782 & 0.749 & 0.652 & 0.611 & 0.673 & 0.699 \\
Sargan & 22.670 & 20.390 & 23.484 & 24.478 & 25.647 & 25.850 & 25.733 & 25.971 \\
& {$[1.000]$} & {$[1.000]$} & {$[1.000]$} & {$[1.000]$} & {$[1.000]$} & {$[1.000]$} & {$[1.000]$} & {$[1.000]$} \\
\multirow{2}{*}{ Wald test } & 2540.90 & 2944.90 & 2961.58 & 8286.19 & 3010.06 & 1925.07 & 13109.21 & 4793.72 \\
& {$[0.000]$} & {$[0.000]$} & {$[0.000]$} & {$[0.000]$} & {$[0.000]$} & {$[0.000]$} & {$[0.000]$} & {$[0.000]$} \\
\hline
\end{tabular}

Note: standard errors in parentheses; ${ }^{*} \mathrm{p}<0.10,{ }^{* *} \mathrm{p}<0.05,{ }^{* * *} \mathrm{p}<0.001$; the numbers in [] are the P-values of the corresponding test statistics.

The moderating effects of TED on the ENV are non-significantly negative. In contrast, the moderating effects of TED on the PDF are significantly positive. A change in environmental management power will change the direction and structure of investment in environmental protection when the degree of ED increases. Under the pressure of economic growth and promotion incentives, local governments tend to invest in environmental projects with short cycles and rapid returns to show their political achievements [40] and decrease environmental protection investment. Less ENV may increase economic growth in a short time but may not significantly promote GTFP growth. Local authorities have an intimate knowledge of local environmental quality (Oates, 1999), and decentralized environmental management contributes to environmental quality if the costs of environmental protection in the local systems are lower than those of the central government (D'Amato and Valentini, 2011).

The establishment of an appropriate scientific management system and overseeing personnel and investments in environmental protection are included in the environmental administrative responsibilities of local governments. Local authorities have flexibility in adjusting the structure of environmental investment depending on regional economic development and promotion incentives [42]. Local governments usually lower environmental protection investment and encourage industrial enterprises to invest in pollution treatment, which increases the cost of enterprise production. Therefore, environmental administrative decentralization may reduce the effectiveness of investment in industrial pollution control on regional GTFP. Besides, with increasing levels of environmental decentralization, local authorities have more autonomy in developing discretionary benchmarks of PDF, which promotes GTFP growth.

The whole coordination of environmental affairs involved in the SED includes the assessment and verification of pollutant discharge, supervision of protective environment, and inspections of environmental law enforcement. Accordingly, the expansion of environmental supervisory power will improve regional GTFP by regulating pollution discharge. However, with the improvement of SED, local governments play a dual role in environmental protection and are engaged in both "law enforcement" and "supervision of law enforcement." Therefore, local governments may improve the efficiency of PDF to avoid conflict between environmental protection and economic interests, thereby indirectly promoting GTFP.

In the environmental management system, the environmental monitoring department is responsible for monitoring and evaluating pollutant emissions. Expansion of environmental monitoring power indicates that local governments have autonomy in self-evaluation of 
environmental quality, and the monitoring data may be modified and adjusted by officials [43] for better political performances. The PDF are the sources of the pollution fund, and there are few incentives to modify the monitoring data for local officials. Therefore, MED has positive moderating effects on PDF.

The Ministry of Environmental Protection created the East China and South China environmental protection supervision centers in 2002. Since then, the northwest, southwest, northeast, and north China supervision centers have been established in succession, indicating greater involvement of the central governments in environmental management. As showing in Figure 3, while the SED showed a slightly increasing trend, the degree of TED, AED, and MED showed a decreasing trend from 2001 to 2015 in China. To sum up, the positive effects of PDF on GTFP are enhanced with an increase in the degree of environmental decentralization between the central and local systems.
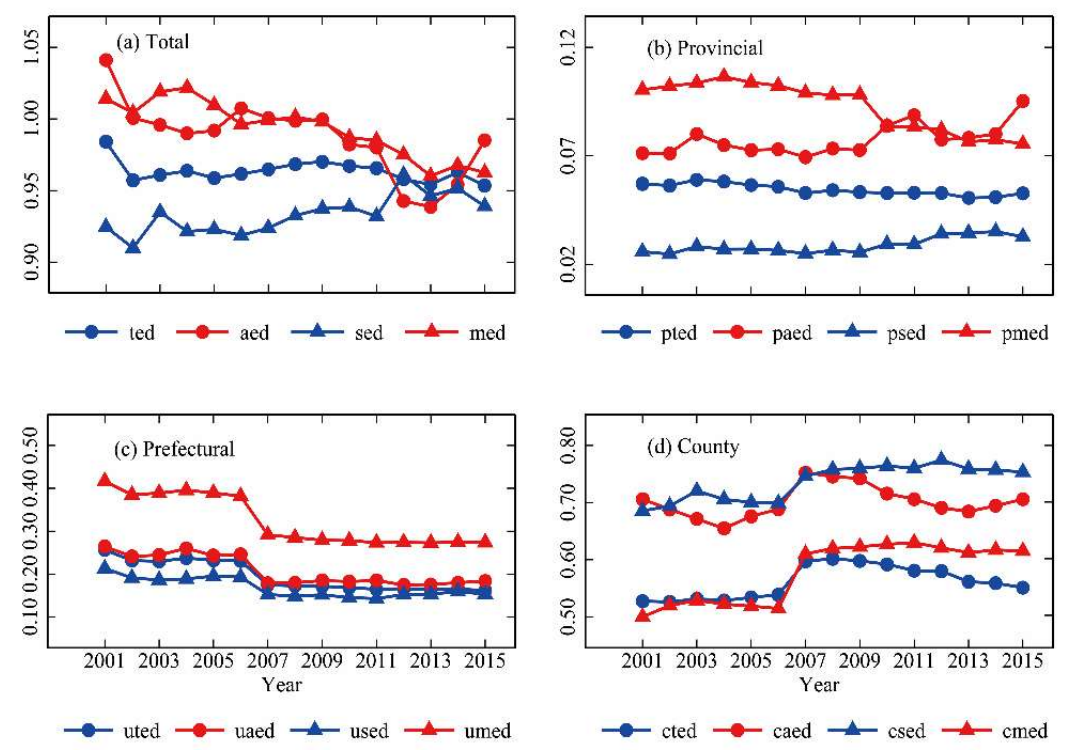

Figure 3. The degree of total environmental decentralization ((a) Total) and the three sub-indicators at different administrative levels ((b) Provincial, (c) Prefectural, (d) County respectively represent the administrative level provincial, prefectural, and county) during 2001-2015.

4.3.2 The moderating effect of environmental decentralization at different administrative levels in a province

The cross-term effects of environmental regulation and environmental decentralization at various administrative levels (provincial, prefectural, and county-level) on the GTFP (Table 4). Regarding environmental decentralization at the provincial level, if all other factors remain unchanged, the GTFP inhibiting effects of ENV are significantly influenced by TED and AED; by contrast, the GTFP inhibiting effects of PDF are significantly influenced by TED and its three subindicators. At the prefectural level, the GTFP inhibiting effects of PDF are influenced considerably by MED, and the other results are not statistically significant. The GTFP promotive effects of ENV are influenced by TED. At the county level, the GTFP inhibiting effects of ENV are significantly influenced by TED and SED, whereas the GTFP promotive effects of PDF are influenced by TED and its sub-indicators.

Table 4. Estimated results of the moderating effects of environmental decentralization at the different administrative levels within a province.

$\begin{array}{lll}\text { Variables } & \text { ENV }\end{array}$




\begin{tabular}{|c|c|c|c|c|c|c|c|c|}
\hline & TED & AED & SED & MED & TED & AED & SED & MED \\
\hline \multicolumn{9}{|c|}{ Provincial } \\
\hline \multirow[t]{2}{*}{$\mathrm{GTFP}_{\mathrm{i}, \mathrm{t}-1}$} & $0.594^{* * *}$ & $0.545^{* * *}$ & $0.557^{* * *}$ & $0.549^{* * *}$ & $0.620^{* * * *}$ & $0.634^{* * *}$ & $0.565^{* * *}$ & $0.627^{* * *}$ \\
\hline & $(0.034)$ & $(0.025)$ & $(0.029)$ & $(0.029)$ & $(0.039)$ & $(0.026)$ & $(0.041)$ & $(0.025)$ \\
\hline \multirow[t]{2}{*}{ ER } & $-0.013^{* * * *}$ & $-0.020^{* * * *}$ & $-0.013^{* * * *}$ & $-0.016^{* * *+}$ & $0.048^{* * *}$ & $0.050^{* * *}$ & 0.008 & $0.063^{* * *}$ \\
\hline & $(0.003)$ & $(0.003)$ & $(0.003)$ & $(0.003)$ & $(0.008)$ & $(0.006)$ & $(0.009)$ & $(0.007)$ \\
\hline \multirow[t]{2}{*}{$E R \times E D$} & $-0.013^{* *}$ & $-0.025^{* *}$ & -0.020 & -0.002 & $-0.041^{* *}$ & $-0.023^{* *}$ & $-0.085^{* * *}$ & $-0.037^{* *}$ \\
\hline & $(0.037)$ & $(0.077)$ & $(0.168)$ & $(0.088)$ & $(0.128)$ & $(0.096)$ & $(0.512)$ & $(0.121)$ \\
\hline \multirow[t]{2}{*}{ ED } & -0.081 & 0.054 & $-0.121^{* *}$ & 0.068 & 0.019 & $-0.048^{* *}$ & -0.102 & 0.167 \\
\hline & $(0.104)$ & $(0.177)$ & $(0.288)$ & $(0.098)$ & $(0.255)$ & $(0.048)$ & $(0.340)$ & $(0.231)$ \\
\hline \multirow[t]{2}{*}{ STRUCT } & 0.027 & 0.021 & 0.019 & $0.062^{* *}$ & $0.046^{*}$ & $0.037^{* *}$ & $0.025^{*}$ & $0.065^{* * *}$ \\
\hline & $(0.055)$ & $(0.040)$ & $(0.050)$ & $(0.057)$ & $(0.050)$ & $(0.035)$ & $(0.032)$ & $(0.049)$ \\
\hline \multirow[t]{2}{*}{ ТECH } & $0.165^{* * *}$ & $0.143^{* *}$ & $0.162^{* * *}$ & $0.250^{* * *}$ & $0.227^{* * * *}$ & $0.232^{* * *}$ & $0.186^{* * *}$ & $0.351^{* * *}$ \\
\hline & $(0.004)$ & $(0.006)$ & $(0.004)$ & $(0.006)$ & $(0.006)$ & $(0.004)$ & $(0.004)$ & $(0.010)$ \\
\hline \multirow[t]{2}{*}{ POPU } & $0.011^{*}$ & 0.009 & $0.015^{* *}$ & $0.023^{* * *}$ & $0.018^{* *}$ & $0.020^{* * *}$ & $0.019^{* *}$ & $0.027^{* *}$ \\
\hline & $(0.001)$ & $(0.002)$ & $(0.001)$ & $(0.002)$ & $(0.002)$ & $(0.002)$ & $(0.002)$ & $(0.002)$ \\
\hline \multirow[t]{2}{*}{ TELE } & $0.056^{* * *}$ & $0.069^{* * *}$ & $0.055^{* * *}$ & $0.053^{* * *}$ & $0.050^{* * * *}$ & $0.054^{* * *}$ & $0.046^{* * *}$ & $0.050^{* * *}$ \\
\hline & $(0.058)$ & $(0.050)$ & $(0.051)$ & $(0.064)$ & $(0.067)$ & $(0.058)$ & $(0.069)$ & $(0.065)$ \\
\hline \multirow[t]{2}{*}{ RGDP } & $-0.126^{* * * *}$ & $-0.096^{*}$ & $-0.111^{* * *}$ & $-0.188^{* * * *}$ & $-0.144^{* * *}$ & $-0.154^{* * *}$ & $-0.112^{* * *}$ & $-0.228^{* * *}$ \\
\hline & $(0.007)$ & $(0.011)$ & $(0.008)$ & $(0.010)$ & $(0.010)$ & $(0.006)$ & $(0.006)$ & $(0.016)$ \\
\hline \multirow[t]{2}{*}{ FDI } & -0.001 & -0.019 & $-0.014^{* * *}$ & -0.018 & $0.004^{* *}$ & $-0.025^{* * *}$ & $-0.016^{* * *}$ & -0.042 \\
\hline & $(0.001)$ & $(0.009)$ & $(0.001)$ & $(0.004)$ & $(0.001)$ & $(0.002)$ & $(0.001)$ & $(0.009)$ \\
\hline AR (1) & $-1.438^{*}$ & $-1.359^{*}$ & $-1.394^{*}$ & $-1.429^{*}$ & $-1.501^{*}$ & $-1.519^{*}$ & $-1.486^{*}$ & $-1.541^{*}$ \\
\hline AR (2) & 0.658 & 0.651 & 0.817 & 0.817 & 0.675 & 0.618 & 1.002 & 0.523 \\
\hline \multirow[t]{2}{*}{ Sargan } & 24.132 & 22.916 & 22.805 & 21.729 & 25.544 & 26.957 & 24.150 & 24.241 \\
\hline & [1.000] & [1.000] & [1.000] & [1.000] & [1.000] & [1.000] & [1.000] & [1.000] \\
\hline \multirow[t]{2}{*}{ Wald test } & 2607.01 & 4176.62 & 2315.55 & 3993.58 & 8236.80 & 7455.87 & 2418.18 & 10896.26 \\
\hline & {$[0.000]$} & {$[0.000]$} & [0.000] & {$[0.000]$} & {$[0.000]$} & {$[0.000]$} & {$[0.000]$} & {$[0.000]$} \\
\hline \multicolumn{9}{|c|}{ Prefectural } \\
\hline \multirow[t]{2}{*}{$\mathrm{GTFP}_{\mathrm{i}, \mathrm{t}-1}$} & $0.570^{* * * *}$ & $0.566^{* * *}$ & $0.529^{* * *}$ & $0.527^{* * *}$ & $0.608^{* * * *}$ & $0.604^{* * *}$ & $0.565^{* * *}$ & $0.591^{* * *}$ \\
\hline & $(0.029)$ & $(0.046)$ & $(0.042)$ & $(0.036)$ & $(0.043)$ & $(0.030)$ & $(0.037)$ & $(0.042)$ \\
\hline \multirow[t]{2}{*}{ ER } & $-0.018^{* * *}$ & $-0.015^{* * *}$ & $-0.010^{*}$ & $-0.014^{* * * *}$ & $0.063^{* * * *}$ & $0.051^{* * *}$ & $0.065^{* * *}$ & $0.066^{* * *}$ \\
\hline & $(0.003)$ & $(0.002)$ & $(0.003)$ & $(0.003)$ & $(0.005)$ & $(0.005)$ & $(0.005)$ & $(0.007)$ \\
\hline \multirow[t]{2}{*}{$E R \times E D$} & $0.021^{*}$ & -0.013 & -0.018 & -0.002 & 0.008 & -0.023 & -0.002 & $-0.033^{* *}$ \\
\hline & $(0.064)$ & $(0.110)$ & $(0.078)$ & $(0.053)$ & $(0.104)$ & $(0.101)$ & $(0.073)$ & $(0.054)$ \\
\hline \multirow[t]{2}{*}{ ED } & $-0.025^{*}$ & $-0.093^{* * *}$ & $-0.064^{* * * *}$ & $-0.056^{* *}$ & $-0.060^{* * *}$ & $-0.085^{* * *}$ & $-0.118^{* * *}$ & $-0.099^{* * *}$ \\
\hline & $(0.018)$ & $(0.025)$ & $(0.031)$ & $(0.026)$ & $(0.030)$ & $(0.020)$ & $(0.040)$ & $(0.029)$ \\
\hline \multirow[t]{2}{*}{ STRUCT } & $0.063^{* * *}$ & $0.050^{*}$ & $0.068^{* * *}$ & $0.077^{* * *}$ & $0.051^{* *}$ & $0.051^{* * *}$ & $0.036^{*}$ & $0.068^{* * *}$ \\
\hline & $(0.045)$ & $(0.054)$ & $(0.052)$ & $(0.055)$ & $(0.045)$ & $(0.038)$ & $(0.039)$ & $(0.045)$ \\
\hline \multirow[t]{2}{*}{$\mathrm{TECH}$} & $0.217^{* * *}$ & $0.175^{* * *}$ & $0.179^{* * *}$ & $0.205^{* * *}$ & $0.252^{* * * *}$ & $0.239^{* * *}$ & $0.178^{* * *}$ & $0.257^{* * *}$ \\
\hline & $(0.005)$ & $(0.004)$ & $(0.004)$ & $(0.004)$ & $(0.003)$ & $(0.004)$ & $(0.004)$ & $(0.004)$ \\
\hline
\end{tabular}




\begin{tabular}{|c|c|c|c|c|c|c|c|c|}
\hline \multirow[t]{2}{*}{ POPU } & $0.019^{* *}$ & 0.001 & $0.022^{* * *}$ & $0.014^{*}$ & $0.015^{*}$ & $0.014^{* *}$ & 0.011 & $0.015^{*}$ \\
\hline & $(0.002)$ & $(0.002)$ & $(0.002)$ & $(0.002)$ & $(0.002)$ & $(0.002)$ & $(0.002)$ & $(0.002)$ \\
\hline \multirow[t]{2}{*}{ TELE } & $0.060^{* * *}$ & $0.051^{* * *}$ & $0.043^{* * * *}$ & $0.047^{* * * *}$ & $0.055^{* * * *}$ & $0.048^{* * *}$ & $0.051^{* * *}$ & $0.047^{* * *}$ \\
\hline & $(0.048)$ & $(0.063)$ & $(0.064)$ & $(0.067)$ & $(0.062)$ & $(0.059)$ & $(0.055)$ & $(0.056)$ \\
\hline \multirow[t]{2}{*}{ RGDP } & $-0.167^{* * * *}$ & $-0.145^{* * *}$ & $-0.168^{* * * *}$ & $-0.179^{* * * *}$ & $-0.179^{* * *}$ & $-0.174^{* * * *}$ & $-0.129^{* * * *}$ & $-0.199^{* * * *}$ \\
\hline & $(0.008)$ & $(0.006)$ & $(0.008)$ & $(0.007)$ & $(0.005)$ & $(0.006)$ & $(0.006)$ & $(0.007)$ \\
\hline \multirow[t]{2}{*}{ FDI } & $0.012^{* *}$ & 0.008 & $0.008^{* *}$ & $0.008^{* *}$ & $0.008^{* * *}$ & $0.007^{* * *}$ & $0.015^{* * *}$ & $0.003^{*}$ \\
\hline & $(0.002)$ & $(0.002)$ & $(0.001)$ & $(0.001)$ & $(0.001)$ & $(0.001)$ & $(0.001)$ & $(0.001)$ \\
\hline AR (1) & $-1.455^{*}$ & $-1.517^{*}$ & $-1.331^{*}$ & $-1.388^{*}$ & $-1.500^{*}$ & $-1.630^{*}$ & $-1.453^{*}$ & $-1.572^{*}$ \\
\hline $\mathrm{AR}(2)$ & 0.882 & 0.815 & 0.878 & 0.907 & 0.613 & 0.797 & 0.774 & 0.713 \\
\hline \multirow[t]{2}{*}{ Sargan } & 25.424 & 24.567 & 22.729 & 22.637 & 26.117 & 25.719 & 24.532 & 26.038 \\
\hline & [1.000] & [1.000] & [1.000] & [1.000] & [1.000] & [1.000] & [1.000] & [1.000] \\
\hline \multirow[t]{2}{*}{ Wald test } & 1398.71 & 3361.84 & 1302.64 & 2230.86 & 5262.14 & 2088.00 & 5001.14 & 3017.99 \\
\hline & {$[0.000]$} & {$[0.000]$} & {$[0.000]$} & {$[0.000]$} & {$[0.000]$} & {$[0.000]$} & {$[0.000]$} & {$[0.000]$} \\
\hline \multicolumn{9}{|l|}{ County } \\
\hline \multirow[t]{2}{*}{$\mathrm{GTFP}_{\mathrm{i}, \mathrm{t}-1}$} & $0.630^{* * * *}$ & $0.539^{* * * *}$ & $0.589^{* * *}$ & $0.590^{* * * *}$ & $0.663^{* * * *}$ & $0.586^{* * * *}$ & $0.638^{* * *}$ & $0.619^{* * *}$ \\
\hline & $(0.021)$ & (0.032) & $(0.029)$ & $(0.036)$ & $(0.029)$ & $(0.025)$ & $(0.032)$ & $(0.034)$ \\
\hline \multirow[t]{2}{*}{ ER } & $-0.023^{*+*+}$ & $-0.022^{* *}$ & $-0.019^{* * * *}$ & $-0.019^{* * * *}$ & $0.063^{* * *}$ & $0.062^{* * * *}$ & $0.075^{* * *}$ & $0.059^{* * *}$ \\
\hline & $(0.003)$ & $(0.006)$ & $(0.003)$ & $(0.003)$ & $(0.005)$ & $(0.004)$ & $(0.004)$ & $(0.004)$ \\
\hline \multirow[t]{2}{*}{$E R \times E D$} & $-0.036^{* *+*}$ & -0.013 & $-0.010^{*}$ & -0.012 & $0.073^{* * *}$ & $0.028^{* * *}$ & $0.067^{* * *}$ & $0.053^{* * *}$ \\
\hline & $(0.025)$ & (0.038) & (0.009) & (0.037) & $(0.022)$ & $(0.015)$ & $(0.010)$ & $(0.015)$ \\
\hline \multirow[t]{2}{*}{ ED } & $-0.035^{*}$ & $0.180^{* * * *}$ & $0.189^{* * *}$ & $0.124^{* * *}$ & $-0.077^{*+* *+}$ & $0.159^{* * *}$ & $0.075^{* * *}$ & $0.065^{* * *}$ \\
\hline & $(0.010)$ & $(0.010)$ & $(0.010)$ & $(0.021)$ & $(0.008)$ & (0.009) & $(0.008)$ & $(0.011)$ \\
\hline \multirow[t]{2}{*}{ STRUCT } & $0.041^{*}$ & $0.057^{* *}$ & 0.013 & 0.021 & $0.067^{* * *}$ & 0.029 & $0.053^{* *}$ & $0.059^{* * *}$ \\
\hline & $(0.046)$ & $(0.052)$ & $(0.051)$ & $(0.049)$ & $(0.036)$ & $(0.051)$ & $(0.047)$ & $(0.047)$ \\
\hline \multirow[t]{2}{*}{$\mathrm{TECH}$} & $0.231^{* * *}$ & $0.224^{* * * *}$ & $0.141^{* * *}$ & $0.183^{* * * *}$ & $0.323^{* * * *}$ & $0.235^{* * *}$ & $0.280^{* * *}$ & $0.312^{* * *}$ \\
\hline & $(0.004)$ & $(0.005)$ & $(0.004)$ & $(0.004)$ & $(0.004)$ & $(0.003)$ & $(0.003)$ & $(0.004)$ \\
\hline \multirow[t]{2}{*}{ POPU } & $0.020^{* * * *}$ & 0.005 & $0.024^{* * *}$ & 0.007 & $0.021^{* *}$ & -0.011 & $0.023^{* * *}$ & $0.038^{* * *}$ \\
\hline & $(0.002)$ & $(0.002)$ & $(0.002)$ & $(0.002)$ & $(0.002)$ & $(0.002)$ & $(0.002)$ & $(0.001)$ \\
\hline \multirow[t]{2}{*}{ TELE } & $0.053^{* * *}$ & $0.047^{* * * *}$ & $0.051^{* * *}$ & $0.053^{* * *}$ & $0.048^{* * *}$ & $0.055^{* * *}$ & $0.056^{* * *}$ & $0.046^{* * *}$ \\
\hline & $(0.050)$ & $(0.060)$ & $(0.056)$ & $(0.057)$ & $(0.065)$ & $(0.048)$ & $(0.049)$ & $(0.067)$ \\
\hline \multirow[t]{2}{*}{ RGDP } & $-0.180^{* * * *}$ & $-0.168^{* * *}$ & $-0.116^{* * * *+4}$ & $-0.156^{* * *}$ & $-0.226^{* * *}$ & $-0.130^{* * *}$ & $-0.190^{* * *}$ & $-0.248^{* * *}$ \\
\hline & $(0.008)$ & $(0.009)$ & $(0.007)$ & $(0.008)$ & $(0.008)$ & $(0.006)$ & $(0.007)$ & $(0.008)$ \\
\hline \multirow[t]{2}{*}{ FDI } & $-0.006^{* * *}$ & $-0.004^{* * *}$ & $-0.004^{*+* x}$ & $-0.002^{* *}$ & $-0.011^{* * *}$ & 0.002 & $-0.003^{* *}$ & $-0.007^{* * *}$ \\
\hline & $(0.000)$ & $(0.000)$ & $(0.000)$ & $(0.000)$ & $(0.000)$ & $(0.001)$ & $(0.000)$ & $(0.000)$ \\
\hline AR (1) & $-1.557^{*}$ & $-1.546^{*}$ & $-1.471^{*}$ & $-1.494^{*}$ & $-1.550^{*}$ & $-1.581^{*}$ & $-1.504^{*}$ & $-1.518^{*}$ \\
\hline AR (2) & 0.634 & 0.685 & 0.855 & 0.746 & 0.714 & 0.564 & 0.738 & 0.816 \\
\hline \multirow[t]{2}{*}{ Sargan } & 23.556 & 25.835 & 24.554 & 25.209 & 25.499 & 26.153 & 28.544 & 24.403 \\
\hline & {$[1.000]$} & [1.000] & [1.000] & [1.000] & [1.000] & [1.000] & [1.000] & [1.000] \\
\hline \multirow[t]{2}{*}{ Wald test } & 16742.83 & 4955.08 & 2060.05 & 1520.13 & 5323.31 & 3807.73 & 6469.36 & 3399.42 \\
\hline & {$[0.000]$} & {$[0.000]$} & {$[0.000]$} & {$[0.000]$} & {$[0.000]$} & [0.000] & {$[0.000]$} & {$[0.000]$} \\
\hline
\end{tabular}


Note: standard errors in parentheses; ${ }^{*} \mathrm{p}<0.10,{ }^{* *} \mathrm{p}<0.05,{ }^{* * *} \mathrm{p}<0.001$; the numbers in [] are the P-values of the corresponding test statistics.

According to the above empirical results, TED should be increased at the prefectural level regarding ENV. Compared with the provincial environmental management system, the prefectural system is more efficient in investing in environmental protection because it is more familiar with local conditions, which reduces the implementation cost of investment. Compared with the county-level environmental management system, the prefectural system can allocate overall investment in industrial pollution treatment. Also, under the supervision of provincial and county governments, the investment in industrial pollution control will promote regional GTFP with increasing provincial environmental decentralization.

Environmental decentralization should be increased at the county level regarding PDF. Compared with the provincial and prefectural government, county-level governments are more efficient in providing public goods and formulating pollution discharge policies owing to the local advantage, thus balancing the relationship between economic growth and environmental protection. For one thing, the strengthening of environmental decentralization may not motivate local environmental protection systems to reduce the standards of PDF that are the source of the pollution treatment funds. For another, compared with provincial and prefectural governments, county-level governments allocate PDF and inspect pollution emissions more efficiently.

In terms of environmental decentralization at different administrative levels in a province, the CTED is the highest (Figure 3), showing an increasing trend before 2008, followed by a decreasing trend. The CTED significantly decreases the negative effects of ENV and the positive effects of PDF. The second-highest proportion was the PTED; therefore, the positive effects of ENV and the negative effects of PDF, with the UTED and the three sub-indicators rapidly declining after 2006. The lowest proportion was the PTED that had experienced slight dynamic fluctuations, which slightly impacted the effects of ENV and PDF.

4.3.3 The moderating effect of environmental decentralization based on the dynamic threshold panel model

There are significant threshold impacts of PTED, UTED, or CTED on the effectiveness of ENV to achieve GTFP, and there are significant threshold impacts of TED or UTED on the effectiveness of PDF to achieve GTFP. If the TED exceeds the threshold, the joint effects of PDF and TED on GTFP are significantly positive. If the PTED crosses the threshold, the joint effects of ENV and PTED on GTFP range from significantly negative to non-significantly positive. If UTED crosses the threshold, the joint effects of ENV and UTED on GTFP vary from non-significantly negative to significantly positive, and the joint effects of PDF and UTED on GTFP vary from significantly negative to non-significantly positive. The joint effects of ENV and CTED on GTFP range from significantly negative to insignificantly positive when CTED crosses the threshold. On the whole, the regression results calculated by the dynamic threshold panel model are consistent with the estimated results in Table 4. The sample distribution shows that at least $95 \%$ of the total samples have exceeded the respective thresholds of environmental decentralization at the different administrative levels, indicating that environmental decentralization through different environmental regulations has significant positive effects on GTFP.

Table 5. Estimation results of the moderating effects based on the dynamic threshold panel model.

\begin{tabular}{cccccc}
\hline Threshold variables and value & \multicolumn{2}{c}{ Estimation results } & \multicolumn{2}{c}{ P-value } \\
\hline & ENV & PDF & ENV & PDF \\
\hline TED $<0.526$ & -0.004 & -0.040 & & \\
& $(0.106)$ & $(0.067)$ & {$[0.838]$} & {$[0.026]$} \\
TED $\geq 0.526$ & -0.023 & $0.087^{* * *}$ & &
\end{tabular}




\begin{tabular}{cccccc} 
& $(0.097)$ & $(0.021)$ & & \\
\cline { 4 - 6 } & $-0.562^{*}$ & 0.309 & & \\
PTED $\leq 0.026$ & $(0.335)$ & $(0.512)$ & & \\
& 0.092 & $-0.511^{*}$ & {$[0.079]$} & {$[0.208]$} \\
& $(0.101)$ & $(0.279)$ & & \\
\hline PTED $>0.026$ & -0.010 & $-0.082^{* * *}$ & & \\
& $(0.148)$ & $(0.192)$ & & \\
& $0.027^{* *}$ & 0.009 & {$[0.066]$} & {$[0.002]$} \\
UTED $\leq 0.000$ & $(0.069)$ & $(0.150)$ & & \\
\hline CTED $\leq 0.231$ & $-0.111^{* *}$ & 0.026 & & \\
& $(0.172)$ & $(0.055)$ & & \\
& 0.045 & $0.054^{* * *}$ & {$[0.050]$} & {$[0.845]$} \\
CTED $>0.231$ & $(0.129)$ & $(0.026)$ & & \\
\hline
\end{tabular}

Note: Standard errors in parentheses; ${ }^{*} \mathrm{p}<0.10,{ }^{* *} \mathrm{p}<0.05,{ }^{* * *} \mathrm{p}<0.001$; the numbers in [] are the P-values of the threshold effect, a threshold effect exists if $\mathrm{P}<0.1$.

Figure 4 presents the calculation results of TED, PTED, UTED, and CTED. Guangxi ranks last in terms of TED, and its degree of TED is lower than 0.526 , which indicates that the positive effects of the PDF on GTFP increase with an improvement in total environmental decentralization. Chongqing ranks last in terms of UTED, and the degree of UTED is 0. With the improvement in total environmental decentralization at the prefectural level, the negative effects of the investment in industrial pollution treatment and the positive effects of PDF on GTFP decrease in Chongqing. In summary, the degree of TED reduces the negative effects of PDF in the eastern provinces and enhances the positive effects of PDF in the central and western provinces (except Guangxi). The degree of UTED enhances the positive effects of ENV, reduces the negative effects of PDF in the eastern provinces, and reduce the negative effects of ENV in the central and western provinces (except Chongqing)

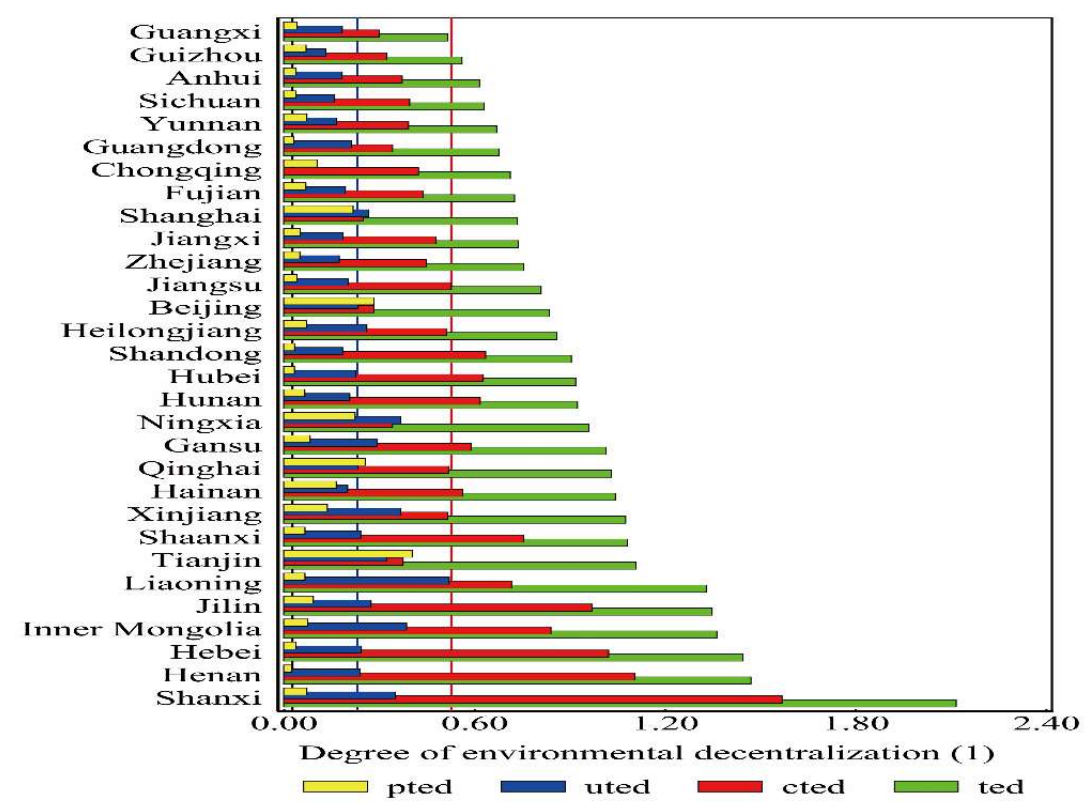

Figure 4. Degree of total environmental decentralization at different administrative levels from 2001 to 2015 in China. The black, red, and red lines indicate the degree 0.026, 0.231, and 0.526, respectively. 


\section{Conclusions and policy implications}

The effects of environmental regulations on GTFP are influenced by environmental decentralization because the environmental management system represents the institutional foundation and precondition of environmental protection. Therefore, the appropriate level of environmental decentralization at different administrative levels is of considerable significance to the development of an efficient environmental management system.

Based on panel data of 30 Chinese provinces from 2001 to 2015, this paper compared TFP and GTFP, and the analysis results are as follows. China's GTFP was higher than TFP, whose average value was slightly less than 1 . The GTFP of the eastern regions was much higher than TFP, and the differences between them have increased over time, indicating that production was moving towards less energy consumption or less pollution. However, the opposite occurred in the central and western regions, where TFP was much higher than GTFP.

DIFF_GMM was employed to estimate the effects of different environmental regulations (ENV and PDF) on GTFP and determine the moderating effect of environmental decentralization on this driving mechanism. the following conclusions were obtained:

First, ENV had negative effects on GTFP improvement, while PDF had significant positive effects on GTFP. This result implies that in China, the pollutant discharge fee plays a crucial role in promoting GTFP. Due to regional heterogeneity, in the east, the positive effects of ENV on GTFP were statistically significant, whereas the negative effects of the PDF on GTFP were significant; however, the opposite occurred in the central and western regions.

Second, TED had no regulatory effect on environmental protection investment but had positive regulatory effects on the PDF. This result indicated that TED and PDF jointly promoted GTFP. In general, the moderating effects of the sub-indices of the TED on environmental regulation were consistent with the results of TED. Specifically, the joint effects of ENV and AED or SED significantly inhibited GTFP growth; by contrast, AED, SED, and SED significantly increased the positive effects of PDF on GTFP.

Third, the regulatory effects of environmental decentralization were estimated innovatively at different administrative levels, i.e., the provincial, prefectural, and county-level, on environmental regulations. The results showed that the joint effects of UTED and ENV significantly promoted GTFP growth. The joint impacts of PDF and CTED significantly increased GTFP growth. However, the joint effects of PTED and its three sub-indicators did not promote GTFP growth.

Fourth, as for moderating effects of environmental decentralization at different administrative levels within a province, the degree of provincial environmental decentralization (PTED) should be decreased because it has negative moderating effects on ENV and PDF, while the degrees of prefectural ED (UTED) and county-level ED (CTED) should be increased.

Based on the above conclusions, policy recommendations are provided. China's interior regions should seize the opportunity for green growth. Significant regional differences in GTFP indicate that China's central and western regions should avoid a model of "pollution first, treatment later." Meanwhile, environmental regulations are useful tools to promote GTFP, and a balanced "environmental regulation mix" system should be established in different regions of China. China's eastern regions should place greater emphasis on environmental protection investment, whereas the central and western areas have primarily focused on pollutant discharge fees.

The environmental decentralization is an institutional foundation and a prerequisite for achieving positive effects of environmental regulations on GTFP. Different environmental decentralization strategies must be formulated to address the heterogeneity of environmental regulations. The level of TED should be decreased in terms of ENV, but it should be increased regarding PDF. Meanwhile, in a province, an appropriate division of environmental management power at the different administrative levels is of great significance to developing an effective environmental management system. The level of PTED should be decreased; however, UTED should be improved regarding ENV, and the level of CTED should be increased regarding PDF.

A quantitative investigation was conducted on the linear effects of environmental regulation on GTFP in China. New research may provide theoretical derivation explaining the empirical results of 
this study. Other environmental regulation tools and their effects on GTFP may provide different results. The quantification of environmental decentralization is not comprehensive and should incorporate the impacts of other social subjects in the future. Meanwhile, the city-level or countylevel data did not only describe the potential heterogeneity between cities or counties in a province but also provided a strong explanation due to the large sample size.

Author Contributions: Zhen Chen: Conceptualization, Methodology, Software, Data curation, Writing - original draft, Visualization, Supervision, Software, Validation, Writing - review \& editing.

Funding: This research was funded by the National Social Science Fund of China, 16BJL051

Conflicts of Interest: The author declares no conflict of interest.

\section{References}

1. Beltrán-Esteve, M.; Giménez, V.; Picazo-Tadeo, A.J. Environmental productivity in the European Union: A global Luenberger-metafrontier approach. Sci. Total Environ. 2019, 692, 136-146, doi:10.1016/j.scitotenv.2019.07.182.

2. Zhang, C.; Liu, H.; Bressers, H.T.A.; Buchanan, K.S. Productivity growth and environmental regulations - accounting for undesirable outputs: Analysis of China's thirty provincial regions using the Malmquist-Luenberger index. Ecol. Econ. 2011, 70, 2369-2379, doi:10.1016/j.ecolecon.2011.07.019.

3. Li, G.; Fang, C.; Wang, S.; Sun, S. The Effect of Economic Growth, Urbanization, and Industrialization on Fine Particulate Matter (PM2.5) Concentrations in China. Environ. Sci. Technol. 2016, 50, 1145211459, doi:10.1021/acs.est.6b02562.

4. Liao, H.; Deng, Q. A carbon-constrained EOQ model with uncertain demand for remanufactured products. J. Clean. Prod. 2018, 199, 334-347, doi:10.1016/j.jclepro.2018.07.108.

5. Peng, X. Strategic interaction of environmental regulation and green productivity growth in China: Green innovation or pollution refuge? Sci. Total Environ. 2020, 732, doi:10.1016/j.scitotenv.2020.139200.

6. Sheng, J.; Zhou, W.; Zhang, S. The role of the intensity of environmental regulation and corruption in the employment of manufacturing enterprises: Evidence from China. J. Clean. Prod. 2019, 219, 244-257, doi:10.1016/j.jclepro.2019.02.113.

7. Qiao, H.; Chen, S.; Dong, X.; Dong, K. Has China's coal consumption actually reached its peak? National and regional analysis considering cross-sectional dependence and heterogeneity. Energy Econ. 2019, 84, doi:10.1016/j.eneco.2019.104509.

8. Guo, L. ling; Qu, Y.; Tseng, M.L. The interaction effects of environmental regulation and technological innovation on regional green growth performance. J. Clean. Prod. 2017, 162, 894-902, doi:10.1016/j.jclepro.2017.05.210.

9. Li, B.; Wu, S. Effects of local and civil environmental regulation on green total factor productivity in China: A spatial Durbin econometric analysis. J. Clean. Prod. 2017, 153, 342-353, doi:10.1016/j.jclepro.2016.10.042. 
10. Kuai, P.; Yang, S.; Tao, A.; Zhang, S.; Khan, Z.D. Environmental effects of Chinese-style fiscal decentralization and the sustainability implications. J. Clean. Prod. 2019, 239, doi:10.1016/j.jclepro.2019.118089.

11. You, D.; Zhang, Y.; Yuan, B. Environmental regulation and firm eco-innovation: Evidence of moderating effects of fiscal decentralization and political competition from listed Chinese industrial companies. J. Clean. Prod. 2019, 207, 1072-1083, doi:10.1016/j.jclepro.2018.10.106.

12. Telle, K.; Larsson, J. Do environmental regulations hamper productivity growth? How accounting for improvements of plants' environmental performance can change the conclusion. Ecol. Econ. 2007, 61, 438-445, doi:10.1016/j.ecolecon.2006.03.015.

13. Manello, A. Productivity growth, environmental regulation and win-win opportunities: The case of chemical industry in Italy and Germany. Eur. J. Oper. Res. 2017, 262, 733-743, doi:10.1016/j.ejor.2017.03.058.

14. Feng, Z.; Chen, W. Environmental regulation, green innovation, and industrial green development: An empirical analysis based on the spatial Durbin model. Sustain. 2018, 10, 223, doi:10.3390/su10010223.

15. Frondel, M.; Horbach, J.; Rennings, K. End-of-pipe or cleaner production? An empirical comparison of environmental innovation decisions across OECD countries. Bus. Strateg. Environ. 2007, 16, 571-584, doi:10.1002/bse.496.

16. OECD Linkages between Environmental Policy and Competitiveness. OECD Environ. Work. Pap. 2010, No. 13, 54, doi:10.1787/218446820583.

17. Jin, P. Theoretical research on the relationship between the regulation of resources and environment and the industrial competitiveness. China Ind. Econ. 2009, 5-17, doi:10.19581/j.cnki.ciejournal.2009.03.001.

18. Levinson, A. Environmental regulatory competition: A status report and some new evidence. Natl. Tax J. 2003.

19. Ran, Q.; Zhang, J.; Hao, Y. Does environmental decentralization exacerbate China's carbon emissions? Evidence based on dynamic threshold effect analysis. Sci. Total Environ. 2020, 721, doi:10.1016/j.scitotenv.2020.137656.

20. Dijkstra, B.R.; Fredriksson, P.G. Regulatory environmental federalism. Annu. Rev. Resour. Econ. 2010, 2, 319-339, doi:10.1146/annurev-resource-040709-135112.

21. Chang, H.F.; Sigman, H.; Traub, L.G. Endogenous decentralization in federal environmental policies. Int. Rev. Law Econ. 2014, 37, 39-50, doi:10.1016/j.irle.2013.07.001.

22. Millimet, D.L. Assessing the empirical impact of environmental federalism. J. Reg. Sci. 2003, 43, 711733, doi:10.1111/j.0022-4146.2003.00317.x. 
23. Wu, H.; Li, Y.; Hao, Y.; Ren, S.; Zhang, P. Environmental decentralization, local government competition, and regional green development: Evidence from China. Sci. Total Environ. 2020, 708, doi:10.1016/j.scitotenv.2019.135085.

24. Secchi, S.; Mcdonald, M. The state of water quality strategies in the Mississippi River Basin: Is cooperative federalism working? Sci. Total Environ. 2019, 677, 241-249, doi:10.1016/j.scitotenv.2019.04.381.

25. Xie, R. hui; Yuan, Y. jun; Huang, J. jing Different Types of Environmental Regulations and Heterogeneous Influence on “Green” Productivity: Evidence from China. Ecol. Econ. 2017, doi:10.1016/j.ecolecon.2016.10.019.

26. Long, X.; Zhao, X.; Cheng, F. The comparison analysis of total factor productivity and eco-efficiency in China's cement manufactures. Energy Policy 2015, 81, 61-66, doi:10.1016/j.enpol.2015.02.012.

27. Blundell, R.; Bond, S. Initial conditions and moment restrictions in dynamic panel data models. J. Econom. 1998, 87, 115-143, doi:10.1016/S0304-4076(98)00009-8.

28. Arčabić, V.; Tica, J.; Lee, J.; Sonora, R.J. Public debt and economic growth conundrum: Nonlinearity and inter-temporal relationship. Stud. Nonlinear Dyn. Econom. 2018, 22, 20, doi:10.1515/snde-2016-0086.

29. Färe, R.; Grosskopf, S.; Pasurka, C.A. Environmental production functions and environmental directional distance functions. Energy 2007, 32, 1055-1066, doi:10.1016/j.energy.2006.09.005.

30. Oh, D. hyun A global Malmquist-Luenberger productivity index. J. Product. Anal. 2010, 34, 183-197, doi:10.1007/s11123-010-0178-y.

31. Li, D.; Wu, R. A dynamic analysis of green productivity growth for cities in Xinjiang. Sustain. 2018, 10, doi:10.3390/su10020515.

32. Lanoie, P.; Patry, M.; Lajeunesse, R. Environmental regulation and productivity: Testing the porter hypothesis. J. Product. Anal. 2008, 30, 121-128, doi:10.1007/s11123-008-0108-4.

33. Hu, W.; Wang, D. How does environmental regulation influence China's carbon productivity? An empirical analysis based on the spatial spillover effect. J. Clean. Prod. 2020, 257, doi:10.1016/j.jclepro.2020.120484.

34. Sigman, H. Decentralization and environmental quality: An international analysis of water pollution levels and variation. Land Econ. 2014, 90, 114-130, doi:10.3368/le.90.1.114.

35. Sjöberg, E.; Xu, J. An Empirical Study of US Environmental Federalism: RCRA Enforcement From 1998 to 2011. Ecol. Econ. 2018, doi:10.1016/j.ecolecon.2018.01.024.

36. Grooms, K.K. Enforcing the Clean Water Act: The effect of state-level corruption on compliance. J. Environ. Econ. Manage. 2015, 73, 50-78, doi:10.1016/j.jeem.2015.06.005. 
37. Xia, F.; Xu, J. Green total factor productivity: A re-examination of quality of growth for provinces in China. China Econ. Rev. 2020, 62, doi:10.1016/j.chieco.2020.101454.

38. Ren, S.; Li, X.; Yuan, B.; Li, D.; Chen, X. The effects of three types of environmental regulation on ecoefficiency: A cross-region analysis in China. J. Clean. Prod. 2018, 173, 245-255, doi:10.1016/j.jclepro.2016.08.113.

39. Balsalobre-Lorente, D.; Shahbaz, M.; Roubaud, D.; Farhani, S. How economic growth, renewable electricity and natural resources contribute to CO2 emissions? Energy Policy 2018, 113, 356-367, doi:10.1016/j.enpol.2017.10.050.

40. Oyono, P.R. Profiling local-level outcomes of environmental decentralizations: The case of Cameroon's forests in the Congo basin. J. Environ. Dev. 2005, 14, 317-337, doi:10.1177/1070496505276552.

41. D'Amato, A.; Valentini, E. Enforcement and environmental quality in a decentralized emission trading system. J. Regul. Econ. 2011, 40, 141-159, doi:10.1007/s11149-011-9153-4.

42. Blomquist, W.; Dinar, A.; Kemper, K.E. A framework for institutional analysis of decentralization reforms in natural resource management. Soc. Nat. Resour. 2010, 23, 620-635,

doi:10.1080/08941920902960396.

43. Jia, R.; Nie, H. Decentralization, collusion, and coal mine deaths. Rev. Econ. Stat. 2017, 99, 105-118, doi:10.1162/REST_a_00563. 